ISSN: 1829-6750 Inovasi Kurikulum, Agustus 2009, Thn. 6. Vol 6 Nomor: 2

\title{
EVALUASI KURIKULUM PENDIDIKAN DASAR: SATU USULAN
}

\section{Erliany Syaodih}

Abstrak: Pendidikan dasar merupakan wilayah fundamental bagi pengembangan sumber daya manusia.KTSP pada Pendidikan Dasar sewajarnya dikembangkan sesuai dengan karakteristik peserta didik, diarahkan pada berbagai tuntutan dan kebutuhannya di masyarakat dan untuk masa depan. Implementasi KTSP untuk Pendidikan Dasar membutuhkan kesiapan berbagai perangkat dan sumber daya manusia, termasuk alat ukur tingkat keberhasilannya. Evaluasi KTSP untuk pendidikan dasar sewajarnya diarahkan pada setiap wilayah kurikulum secara terintegrasi, baik dari sisi ide, dokumen, desain, implementasi dan perangkat-perangkat kurikulum. Kendati saat ini implementasi KTSP pada tingkat Pendidikan Dasar belum sempurna namun selayaknya perangkat evaluasi sudah disiapkan.

Kata Kunci: Evaluasi, Pendidikan Dasar

\section{A. Pendahuluan}

Pendidikan dasar merupakan jenjang pendidikan yang sangat mendasari fundamental, selanjutnya , yaitu pendidikan menengah dan tinggi. Jenjang pendidikan dasar dimanifestasikan dalam bentuk sekolah dasar (SD) dan Madrasah Ibtidaiyah (MI) serta sekolah menengah pertama (SMP) dan Madrasah Tsanawiyah (MTs)

Fungsi pendidikan dasar secara umum diarahkan pada penanaman nilai, sikap dan rasa keindahan, memberikan 
ISSN: 1829-6750 Inovasi Kurikulum, Agustus 2009, Thn. 6 . Vol 6 Nomor: 2

dasar-dasar

pengetahuan,kemampuan dan kecakapan dalam membaca, menulis dan berhitung dalam kapasitas siswa untuk melanjutkan pendidikannya ke pendidikan menengah dan atau hidup di masyarakat , sebagaimana menjadi sasaran pendidikan nasional ( $\mathrm{Bab}$ IV bagian 1 pasal 12 ayat 1 ).

Guna mendukung fungsi tersebut, secara khusus pendidikan dasar diarahkan pada empat modal dasar yang diperlukan siswa untuk kehidupannya, yaitu:

1. Pengembangan Pribadi

Pengembangan pribadi merupakan

pengembangan aspekaspek yang berkenaan dengan kehidupannya sebagai individu.Aspek yang dikembangkan berkenaan dengan seluruh kepribadiannya , baik secara fisik-motorik, intelektual, sosial, maupun afektif yang dimanifestasikan pada pengembangan diri, kemandirian, kemampuan menjaga dan memelihara diri. Proses pendidikan dan pembelajaran pada jenjang pendidikan dasar harus memberikan dasardasar yang kuat bagi pengembanga aspek ini, agar lulusannya memiliki kepribadian yang sehat dan kuat.

2. Pengembangan Kemampuan Sosial

Pengembangan kemampuan sosial diarahkan pada penguasaan kemampuan dalam berinteraksi sosial, menjalin hubungan , kerjasama serta berkomunikasi dengan orang lain. Keluasan jalinan hubungan sosial anak berkembang sejajar dengan perkembangan sosial serta keluasan lingkungan tempat mereka beraktivitas. Pendidikan dan pembelajaran yang diberikan pada jenjang 
ISSN: 1829-6750 Inovasi Kurikulum, Agustus 2009, Thn. 6 . Vol 6 Nomor: 2

pendidikan dasar harus memberikan dasar-dasar yang kuat bagi anak agar mereka mampu hidup, berinteraksi, bekerjasama dan berkomunikasi secara sehat, saling mendorong dan membantu dalam kemajuan dan kemaslahatan bersama.

3. Pembekalan Lanjutan Studi Pendidikan untuk selayaknya memberikan dasar-dasar penguasaan pengetahuan, kecakapan dan keterampilan yang dibutuhkan dalam belajar untuk pendidikan lanjutannya. Pemberian dasar-dasar yang kuat pada jenjang pendidikan dasar akan menjadi pijakan atau fundamen pada pendidikan lanjutannya dan untuk kebutuhan tersebut maka kurikulum harus disajikan secara berkesinambungan, antara kurikulum TK, SD/MI, SMP/MTs, SMU/ MA.
4. Persiapan Pengembangan Karir

Pendidikan dasar memiliki fungsi dalam memberikan dasar-dasar pada siswa untuk memasuki dunia kerja. Pendidikan dasar belum memberikan

pengetahuan,kemampuan atau keterampilan kerja, tetapi dasar-dasarnya diletakkan pada jenjang ini. Disiplin, kejujuran,keteraturan,sem angat, kerjasama, tanggungjawab dll, merupakan karakteristik pribadi yang menjadi dasar untuk dapat dikembangkan pada pendidikan lanjutannya. Dasar-dasarnya perlu diberikan sedini mungkin pada jenjang pendidikan dasar.

Keempat fungsi tersebut selanjutnya diarahkan kepada membangun landasan bagi berkembangnya potensi siswa agar menjadi manusia 
ISSN: 1829-6750 Inovasi Kurikulum, Agustus 2009, Thn. 6 . Vol 6 Nomor: 2

beriman dan bertaqwa, lulusannya di masyarakat. berahlak mulia, sehat, Pendidikannya juga harus berilmu, cakap, kritis, kreatif, mempertimbangkan inovatif, mandiri, percaya diri keragaman kelompok peserta serta menjadi warga negara didik pada masing-masing yang demokratis. Untuk jenjang dan karakteristik sekolah dasar sasaran lebih satuan pendidikannya. Sa'ud terfokus pada perilaku ,U.S dan Soemantri, M. berbudi pekerti, berahlak (2007: 1120) menyatakan mulia dengan menumbuhkembangkan kemahiran menulis, membaca ,berhitung , memecahkan masalah, berfikir logis, kritis dan kreatif. Siswa juga diharapkan memiliki sikap toleran, bertanggungjawab, mandiri serta cakap secara emosional; memiliki dasardasar keterampilan hidup,berwiraswasta, etos kerja serta cinta terhadap bangsa dan tanah air.

Pendididkan dasar bukan hanya diarahkan untuk keperluan saat ini, di masa depan pendidikan dasar perlu diarahkan untuk mengakomodasi kualitas sumber daya manusia yang diperlukan untuk kehidupan bahwa pendidikan dasar selayaknya dipandang sebagai esensi kehidupan, baik bagi perkembangan pribadi maupun masyarakat. Misi pendidikan dasar sebaiknya diarahkan untuk mengembangkan sepenuhnya semua bakat individu, mewujudkan potensi kreatif, termasuk tanggung jawab terhadap hidupnya sendiri. Pengembangan program belajar pada tingkat pendidikan dasar harus meliputi hal-hal esensial yang dibutuhkan peserta didik diwarnai oleh kosep life skill, menggunakan strategi "belajar sepanjang hayat" ", menekankan dasar belajar pada konsep learning to live together ,serta meliputi 
ISSN: 1829-6750 Inovasi Kurikulum, Agustus 2009, Thn. 6 . Vol 6 Nomor: 2

demensi-demensi berikut:

1. Pengembangan individu aspek-aspek hidup pribadi, (dimensi pribadi), meliputi:

a. Relegi: kesadaran beragama

b. Fisik: kesehatan jasmani dan pertumbuhan.

c. Emosi: kesehatan mental dan stabilitas emosi.

d. Etika : integritas moral

e. Estetika: pengajaran kulrual dan rekreasi

2. Pengembangan cara berfikir dan tehnik memeriksa kecerdasan yang terlatih (dimensi kecerdasan) , meliputi :

a. Penguasaan pengetahuan berupa konsep dan informasi

b. Komunikasi pengetahuan : keterampilan untuk memperoleh dan menyampaikan informasi.

c. Pencapaian pengetahuan : cara pemeriksaan,

diskriminasi dan imaginasi.

d. Hasrat akan pengetahuan : kesukaan akan belajar.

3. Penyebaran warisan budaya nilai-nilai civic dan moral bangsa (dimensi sosial), meliputi:

a. Hubungan antara manusia: kerjasama, toleransi

b. Hubungan individunegara : hak, dan kewajiban civil, kesetiaan dan patriotisme, solidaritas nasional.

c. Hubungan individudunia : hubungan antar bangsa, pemahaman dunia.

d. Hubungan individulingkungan hidupnya : ekologi.

4. Pemenuhan kebutuhan sosial yang vital dan menyumbang kepada kesejahteraan ekonomi, 
ISSN: 1829-6750 Inovasi Kurikulum, Agustus 2009, Thn. 6. Vol 6 Nomor: 2

sosal, dan politik lapangan tehnik (dimensi produktif)

a. Pilihan pekerjaan informasi dan bimbingan

b. Persiapan bekerja: latihan dan penempatan

5. Rumah dan keluarga : mengatur rumah tangga, keterampilan mengerjakan sesuatu sendiri, perkawinan.

6. Konsumen : membeli, menjual dan investasi.

\section{B. Kajian Pustaka}

1. Kurikulum Pendidikan Dasar

Pemberlakukan UndangUndang Republik Indonesia Nomor 32 tahun 2004 tentang Pemerintah Daerah menuntut pelaksanaan otonomi daerah dan wawasan demokrasi dalam penyeleng-garaan pendidikan. Hal tersebut diakomodasi dengan diterapkannya kebijakan baru dalam penyusunan kurikulum oleh satuan pendidikan ( sekolah dan perguruan tinggi) dalam bentuk KTSP sebagai pedoman operasional penyusunan kurikulum oleh satua pendidikan.

Permen Nomor 24 tahun 2006 mengeluarkan ke-bijakan baru dimana kurikulum tidak lagi disusun seluruhnya oleh pusat. Tugas pusat ( BSNP) hanya merumuskan standar kom-petensi lulusan (SKL), kerangka dasar kurikulum, struktur dan panduan penyusunan kurikulum pada tingkat satuan pendidikan. Kelengkapan kurikulum lainnya, yaitu penyusunan indikator, penguasaan kompetensi, silabus, satuan pelajaran ( RPP), rencana evaluasi dll, dikembangkan oleh sekolah.

Penyusunan kurikulum satuan pendidikan tertentu selayaknya dikembangkan sesuai dengan visi, misi tujuan , kondisi dan ciri khas satuan pendidikannya namun 
ISSN: 1829-6750 Inovasi Kurikulum, Agustus 2009, Thn. 6 . Vol 6 Nomor: 2

tetap berpegang pada prinsipprinsip yang benar. Beberapa prinsip

penyusunan

kurikulum pendidikan dasar adalah sebagai berikut

1) Berpusat pada potensi, perkembangan, kebutuhan dan kepentingan peserta didik dan lingkungannya.

2) Beragam dan terpadu,

3) Tanggap tehadap perkembangan ilmu pengetahuan, teknologi dan seni,

4) Relevan dengan kebutuhan kehidupan,

5) Menyeluruh dan berkesinambungan,

6) Belajar sepanjang hayat,

7) Seimbang anatara kepentingan nasional dan daerah.

Keseluruhan materi kurikulum yang jadi muatan matamata pelajaran pada pendidikan dasar dan menengah dibagi atas lima kelompok mata pelajaran sebagaimana disajikan sebagai berikut:
Tabel.1

Kelompok dan Muatan Mata Pelajaran

\begin{tabular}{|c|c|}
\hline $\begin{array}{c}\text { Kelompok Mata } \\
\text { Pelajaran }\end{array}$ & Muatan/ Kegiatan \\
\hline $\begin{array}{l}\text { 1. Agama dan } \\
\text { ahlak mulia }\end{array}$ & $\begin{array}{l}\text { 1. agama, kewarganegaraan, } \\
\text { kepribadian, ipteks, } \\
\text { estetika, penjas, olah raga } \\
\text { dan kesehatan }\end{array}$ \\
\hline $\begin{array}{l}\text { 2. Kewarganegara } \\
\text { an dan akhlak } \\
\text { kepribadian }\end{array}$ & $\begin{array}{l}\text { 2. agama, akhlak mulia, } \\
\text { kewarganegaraan, bahasa- } \\
\text { seni-budaya, penjas. }\end{array}$ \\
\hline $\begin{array}{l}\text { 3. Ilmu } \\
\text { pengetahuan } \\
\text { dan teknologi }\end{array}$ & $\begin{array}{l}\text { 3. bahasa, matematika, ipa, } \\
\text { ips, keterampilan, } \\
\text { kejuruan, teknologi } \\
\text { informasi, komunikasi , } \\
\text { muatan lokal. }\end{array}$ \\
\hline 4. Estetika & $\begin{array}{l}\text { 4. bahasa, seni-budaya, } \\
\text { keterampilan dan mulok. }\end{array}$ \\
\hline $\begin{array}{l}\text { 5. Jasmani, olah } \\
\text { raga kesehatan }\end{array}$ & $\begin{array}{l}\text { 5. pendidikan jasmani, olah } \\
\text { raga, kesehatan, ipa dan } \\
\text { munlok. }\end{array}$ \\
\hline
\end{tabular}

Berpegang

pada

pengelompokkan

mata pelajaran yang telah diuraikan tersebut selanjutnya telah tersusun kerangka dasar dan struktur kurikulum SD/MI dan SLTP/ MTs sebagai berikut: 
ISSN: 1829-6750 Inovasi Kurikulum, Agustus 2009, Thn. 6. Vol 6 Nomor: 2

Tabel 2

Struktur Kurikulum SD/MI

\begin{tabular}{|l|l|c|c|c|c|c|c|}
\hline \multirow{2}{*}{ No } & \multirow{2}{*}{ KOMPONEN } & \multicolumn{3}{|c|}{ Kelas\& Alokasi } & \multicolumn{3}{c|}{ Waktu } \\
\cline { 3 - 8 } & & I & II & III & IV & V & VI \\
\hline 1 & Pendidikan Agama & & & & & 3 & \\
2 & Pendidikan Kewarganegaraan & & & & & 2 & \\
3 & Bahasa Indonesia & & & & & 5 & \\
4 & Matematika & & & & & 5 & \\
5 & Ilmu Pengetahuan Alam & & & & & 4 & \\
6 & Ilmu Pengetahuan Sosial & & & & & 3 & \\
7 & Seni dan Budaya & & & & & 4 & \\
8 & Penjas, OR dan Kesehatan & & & & & 4 & \\
\hline B & Muatan Lokal & & & & & 2 & \\
\hline C & Pengembangan Diri & & & & & $2 *$ & \\
\hline & Jumlah & 26 & 27 & 28 & & 32 & \\
\hline
\end{tabular}

Tabel 3

Struktur Kurikulum SMP/MTs

\begin{tabular}{|c|l|c|c|c|}
\hline No & \multicolumn{1}{|c|}{ Komponen } & VII & VIII & IX \\
\hline 1 & Pendidikan Agama & 2 & 2 & 2 \\
2 & Pendidikan Kewarganegaraan & 2 & 2 & 2 \\
3 & Baha Indonesia & 4 & 4 & 4 \\
4 & Bahasa Inggris & 4 & 4 & 4 \\
5 & Matematika & 4 & 4 & 4 \\
6 & IPA & 4 & 4 & 4 \\
7 & IPS & 4 & 4 & 4 \\
8 & Seni dan Budaya & 2 & 2 & 2 \\
9 & Penjas, OR dan Kesehatan & 2 & 2 & 2 \\
10 & Keterampilan/ TI dan Komunikasi & 2 & 2 & 2 \\
& & 2 & 2 & 2 \\
\hline B & Muatan Lokal & $2 *)$ & $2 *)$ & $2 *)$ \\
\hline C & Pengembangan Diri & 32 & 32 & 32 \\
\hline & Jumlah & &
\end{tabular}


ISSN: 1829-6750 Inovasi Kurikulum, Agustus 2009, Thn. 6 . Vol 6 Nomor: 2

Pada kelas-kelas rendah (I-III) digunakan model pengorganisasian kurikulum yang bersifat terintegrasi. Dalam model kurikulum ini tidak ada namanama mata pelajaran yang terpisah sebagaimana disajikan di kelas V sampai VI. Isi atau materi kurikulum dirumuskan dalam bentuk tema-tema.

Tema-tema tersebut bukan saja mengintegrasikan materi berbagai mata pelajaran ( Bahasa, IPA, IPS , Matematika) namun juga mengintegrasikan ranahranah tujuan pembelajaran (kognitif, afektif psikomotor). Model kurikulum ini dalam pembelajarannya juga menggunakan pembelajaran tematik, materi pelajaran dipelajari secara terpadu dengan pembelajaran yang bervariasi. Dari aspek psikologis, model kurikulum terintegrasi memang cocok digunakan pada kelas-kelas rendah di sekolah dasar karena sesuai dengan salah satu prinsip perkembangan , bahwa perkembangan dimulai dari yang bersifat umum menuju khusus. Sejalan dengan hal tersebut maka sangat tepat bila pada tingkat TK dan SD kelas rendah digunakan model kurikulum terintegrasi-tematik.

Pembelajaran tema-tik, sepertihalnya pembel-ajaran lain sangat dianjurkan menggunakan pendekatan multi metode-multi media dengan model-model dan metode pembelajaran yang mengaktifkan siswa.

Kurikulum pendidikan dasar juga menyajikan pelajaran Pengembangan Diri sebagai salah satu aspek yang perlu dikembangkan. Salah satu fungsi utama sekolah adalah membantu dalam pengembangan diri, yaitu pengembangan pribadi sebagai individu. Integritas dan kesehatan pribadi anak sebagai individu, mendasari perkembangan lainnya, baik kemampuan sosial, kesiapan 
ISSN: 1829-6750 Inovasi Kurikulum, Agustus 2009, Thn. 6 . Vol 6 Nomor: 2

untuk melanjutkan studi maupun pengembangan karir.

Pengembangan diri diarahkan pada pengembangan kepribadian anak secara utuh, mandiri dan produktif. Pribadi yang utuh adalah pribadi yang seimbang, harmonis dalam berbagai aspek perkembangannya. Pribadi mandiri adalah pribadi yang mampu

memelihara, memenuhi sendiri. mengurus, menjaga, kebutuhan-nya produktif adalah pribadi yang mampu menghasilkan sesuatu pemikiran, rencana, hasil karya, mampu memberikan bantuan, layanan, jasa serta kebaikan kepada orang lain. Guru-guru dalam setiap pembelajarannya dapat membantu pengembangan aspek ini. Guru pembina kegiatan ekstra kurikuler dapat mengembangkannya melalui berbagai kegiatan ekstra kurikuler.
2. Pentingnya Evaluasi Kurikulum

\section{Pendidikan Dasar}

Bagi

Pendidikan dasar berkenaan dengan pendidikan pada tingkat dasar yang diarahkan pada dua sasaran utama yang sangat strategis, yaitu pengembangan pribadi dan kemampuan sosial. Dua wilayah sasaran yang dalam upaya pencapaiannya membutuhkan dukungan perangkat, sistem serta proses pembelajaran yang sesuai untuk berbagai kebutuhan dan tidak ketinggalan jaman.

Kurikulum pendidikan dasar berkaitan

dengan pengembangan manusia , berupa pengembangan pribadi, potensi, dan kemampuan siswa yang direalisasikan dalam berbagai bentuk kegiatan atau perbuatan belajar. Siswa pada pendidikan dasar adalah manusia yang unik, memiliki karakteristik, perkembangan kemampuan serta cara-cara berinteraksi atau belajar 
ISSN: 1829-6750 Inovasi Kurikulum, Agustus 2009, Thn. 6 . Vol 6 Nomor: 2

tersendiri. Kebaikan desain kurikulum, dalam arti kesesuaian dengan tuntutan lapangan dan ketepatan perumusannya sama pentingnya dengan kebaikan proses kurikulum atau proses implementasinya. Inti dari implementasi kurikulum adalah pembelajaran dalam arti luas sebab pembelajaran dapat berlangsung di dalam dan luar kelas namun masih dalam lingkungan sekolah atau di luar sekolah ( di rumah, di masyarakat atau pusat-pusat sumber belajar). Pembelajaran dapat berlangsung dengan atau tanpa guru, mengkaji teori atau praktek, yang diberikan, diarahkan, ditugasi guru atau atas inisiatif sendiri (hidden curriculum). Pembelajaran yang baik bukan hanya diarahkan pada kemampuan penyeleseian tugas-tugasnya di masa depan tetapi prosesnya disesuaikan dengan karakteristik dan kemampuan peserta didik dengan menempatkan siswa sebagai subyek belajar sehingga kesesuaian implementasi kurikulum, khususnya proses pem-belajaran dengan tuntutan dan kebutuhan lapangan serta karakteristik dan kemampuan siswa perlu secara berkala dievaluasi.

Keberhasilan program serta tercapainya tujuan dan sasaran pendidikan dasar tidak hanya ditentukan oleh ketepatan dan kebaikan desain atau implementasi kurikulum (pembelajaran) namun juga ketersediaan sarana prasarana , fasilitas, media dan sumber belajar. Guna menjamin kontinuitas serta kemudakhan dalam melakukan penyempurnaan maka seluruh komponen, baik desain, implementasi serta faktorfaktor penunjang lain perlu dievaluasi secara berkala. Hanya dengan evaluasi (dan penyem-purnaan) yang kontinu terhadap aspek-aspek tersebut maka proses dan hasil pendidikan sebagaimana 
ISSN: 1829-6750 Inovasi Kurikulum, Agustus 2009, Thn. 6 . Vol 6 Nomor: 2

diuraikan di atas dapat dicapai.

\section{Teori dan Evaluasi Kurikulum}

Kurikulum merupakan bidang kajian yang sangat luas, terbukti banyaknya definisi dan konsep yang dikemukakan berbagai ahli. Sebagian teori menekankan kurikulum sebagai rencana, sedang yang lain pada inovasi, dasar-dasar filosofis atau konsep-konsep yang diambil dari ilmu perilaku manusia. Secara sederhana teori kurikulum diklasifi-kasikan pada isi kurikulum,situasi pendidikan dan organisasi kurikulum.

Penekanan pada isi kurikulum merupakan strategi pengembangan yang paling lama dan banyak digunakan namun me-merlukan banyak pe-nyempurnaan.

Pengembangan kurikulum yang menekankan isi bersifat material centered. Kurikulum memandang siswa sebagai penerima resep yang pasif. Kurikulum bisa diukur, memiliki tujuan, yang apabila telah ditransfer kepada siswa maka dapat dikuasai siswa. Hal ini merupakan engineering approach .

Konsep kurikulum yang menekankan isi, memberi perhatian besar pada analisis pengetahuan baru yang ada, membutuhkan waktu saat mempersiapkan situasi belajar dan menyatukannya dengan tujuan pengajaran yang cukup lama. Kurikulum ini sangat mengutamakan peranan desiminasi. Meskipun belum tentu merupakan produk kurikulum yang baik namun kurikulum menekankan isi dapat dipaksakan melalui birokrasi. Tipe kurikulum ini mengikuti model penyebaran dari pusat ke daerah.

Teori kurikulum dengan penekanan situasi pendidikan lebih menekankan pada masalah , bersifat khusus, sangat memperhatikan dan 
ISSN: 1829-6750 Inovasi Kurikulum, Agustus 2009, Thn. 6 . Vol 6 Nomor: 2

disesuaikan

lingkungan. Kurikulum tipe ini menghasilkan kurikulum berdasarkan lingkungan sehingga dapat merefleksikan dunia kehidupan dari lingkungan siswa. Kurikulum tipe ini kurang menekankan pada spesifikasi isi dan organisasi namun lebih menunjukkan fleksibilitas dalam interpretasi dan pelaksanaannya. Kurikulum disusun sesuai keadaan. Pengembangan kurikulumnya bersifat lokal individu dan khas.

Tipe ketiga adalah tipe kurikulum yang menekankan organisasi., yang sangat menekankan proses belajar mengajar. Tipe kurikulum ini sangat memberi perhatian pada sosok siswa. Konsep belajarnya sangat menekankan siswa aktif namun bukan aktifitas yang sudah diprogramkan ketat.Siswa dengan kesempatan dan di doronng untuk berinovasi serta menyatakan

kreatifitasnya.Tipe kurikulum ini secara relatif bersifat lepas dari siatuasi lingkungan dengan inti kurikulum bukan pada bahan yang dipelajari siswa tetapi pada teacher guide.

Perbedaan tiga konsep tersebut di atas pada akhirnya menimbulkan perbedaan dalam rancangan evaluasinya. Model evaluasi komparatif atau menekankan objektif sangat sesuai bagi kurikulum yang bersifat rasional dan menekankan isi. Evaluasi untuk kurikulum yang menekankan situasi lebih sulit disusun karena kontek evaluasi lebih komplek, banyak tujuan. Dengan menggunakan konsep Ralph Tylor atau Benyamin Bloom bisa dibuat suatu modifikasi dengan menyusun tujuan yang bersifat universal yang dapat digunakan pada semua situasi, walaupun untuk tujuan yang bersifat umum lebih sulit menyusun alat 
ISSN: 1829-6750 Inovasi Kurikulum, Agustus 2009, Thn. 6. Vol 6 Nomor: 2

evaluasinya. Pada kurikulum yang menekankan organisasi, tugas evaluasi lebih sulit lagi karena isi dan hasil kurikulum bukan hal yang utama, hal utamanya adalah aktivitas dan kemampuan siswa.Salah satu solusi untuk masalah itu adalah dengan pendekatan yang besifat elektik.

Model evaluasi kurikulum berkaitan erat dengan konsep kurikulum digunakan.Model-model evaluasi yang digunakan bertumpu pada aspek-aspek tertentu yang diutamakan dalam proses pelaksanaan kurikulum. Model evaluasi yang bersifat komparatif berkaitan erat dengan tingkah laku individu, evaluasi yang menekankan tujuan berkaitan erat dengan kurikulum yang menekankan bahan ajar (isi) kurikulum.

Model antropologis dalam evaluasi ditujukan untuk menekankan tingkah laku dalam suatu lembaga sosial. Dengan demikian sesungguhnya ada hubungan yang sangat erat antara evaluasi dengan kurikulum sebab teori kurikulum juga merupakan teori dari evaluasi kurikulum .

\section{Pembahasan}

Hasan, S.H. menyatakan bahwa evaluasi kurikulum untuk Tingkat Satuan Pendidikan dikembangkan dan mengacu pada pengembangan kurikulum satuan pendidikannya. Pendidikan dasar dalam bentuk SD/MI dan SLTP/MTs merupakan satu satuan pendidikan yang saharusnya menyajikan kurikulum sesuai potensi dan kondisi di wilayahnya masing-masing serta memperhatikan sepuluh prinsip pengembangan KTSP. Dengan asumsi tersebut maka pengembangan evaluasi kurikulum bagi pendididkan dasar selayaknya diarahkan pada 1) evaluasi terhadap ide kurikulum, 2) dokumen kurikulum, 3) silabus, 4) proses (implementasi) kurikulum, dan 5) hasil belajar. Walaupun demikian 
ISSN: 1829-6750 Inovasi Kurikulum, Agustus 2009, Thn. 6. Vol 6 Nomor: 2

pendapat lain dari Syaodih , N.S membagi evaluasi atas tiga masa, yaitu 1) evaluasi desain kurikuum, 2) evaluasi implementasi kurikulum dan 3) evaluasi terhadap faktorfaktor penunjang dalam implementasi kurikulum.

Menggabungkan dua pendapat tersebut, dengan anggapan kondisi pendidikan dasar saat ini maka model evaluasi kurikulum yang digunakan diarahkan pada evaluasi isi. Konsep evaluasi kurikulum pendidikan yang dimaksud dalam tulisan ini diarahkan pada pendidikan dasar berwujud KTSP masa transisi karena sebagian besar lembaga pendidikan dasar saat ini masih belum sepenuhnya menjalankan seraca terintegrasi konsep KTSP sesuai harapan pemerintah. Adanya keragaman sistem penyelenggaraan di lapangan menempatkan evaluasi kurikulum yang disajikan masih bersifat temporer.

\section{Evaluasi Ide Kurikulum}

Ide kurikulum merupakan rumusan filosofi pendidikan yang dianut, pandangan teoritik tentang konsep kurikulum , model kurikulum yang digunakan , konsep tentang konten, organisasi kurikulum, desain kurikulum serta posisi siswa dalam belajar ( Hasan, S.H, 2008 : 121). Evaluasi kurikulum pendidikan dasar pada tatanan ide selayaknya diarahkan dan mengacu pada ide-ide tersebut. Beberapa komponen yang perlu dievaluasi berkenaan dengan:

a) relevansi ide kurikulum dengan masyarakat.

b) kejelasan rumusan ide kurikulum.

c) pemahaman ide oleh tim pengembang kurikulum.

Pada kurikullum berstandar nasional, dengan model kompetensi maka evaluasi kurikulum juga harus diarahkan pada: 
ISSN: 1829-6750 Inovasi Kurikulum, Agustus 2009, Thn. 6 . Vol 6 Nomor: 2

a) teori pendidikan yang kelas, laboratorium ,dan dianut dalam mengem- dana). Komponen mana yang bangkan ide kurikulum akan dipilih untuk evaluasi nasional menjadi ide pendidikan dasar, tampaknya kurikulum pendidika dasar.

b) model kurikulum yang dipilih.

c) teori belajar yang dianut, serta

d) kebijakan evaluasi belajar yang digunakan

tergantung

pada

pengembangan kurikulum yang dianut oleh masingmasing sekolah.

Bagi pendidikan dasar, berdasarkan hasil loka karya Evaluasi KTSP di JICA

2. Evaluasi Desain (Dokumen) Kurikulum

Evaluasi desain kurikulum dapat dirancang lengkap , mencakup kurikulum, dasar-dasar struktur kurikulum, sebaran mata pelajaran, silabus, RPP, rancangan media, dan evaluasi atau terbatas pada komponen tertentu saja seperti silabus dan RPP saja. Kendati demikian Hasan mengarahkan evaluasi dokumen untuk tujuan, proses pembelajaran, isi kurikulum , assesmen serta komponen pendukung (seperti buku, sumber informasi, alat dan suasana tanggal 20 Nopember 2008 evaluasi terhadap dokumen KTSP Pendidikan dasar diarahkan pada komponen visi, misi, tujuan satuan pendidikan, struktur kurikulum, kalender pendidikan, silabus dan RPP. Evaluasi struktur kurikulum berkaitan dengan mata pelajaran, muatan lokal, kegiatan pengembangan diri, beban belajar dengan paket,beban belajar dengan SKS, ketuntasan belajar, kenaikan dan kelulusan, penjurusan, pendidikan kecakapan hidup, pendidikan berbasis keunggulan lokal dan global. Silabus berkenaan 
ISSN: 1829-6750 Inovasi Kurikulum, Agustus 2009, Thn. 6 . Vol 6 Nomor: 2

dengan pengkajian Standar Kompetensi dan Kompetensi Dasar; materi pokok/ pembelajaran pengembangan pembelajaran; indikator kompetensi ; jenis penilaian; alokasi waktu dan sumber belajar. Selanjutnya RPP berkaitan dengan Kompetensi Dasar, indikator, materi pembejaran kegiatan pembelajaran, media dan evaluasi hasil belajar. Seluruh komponen dan sub komponen tersebut selanjutnya dijabarkan dalam berbagai indikator evaluasi. belajaran. Kegiatan yang langsung berhubungan dengan proses pembelajaran adalah pembuatan persiapan mengajar, media dan evaluasi, pelaksanaan pem-belajaran teori, praktek, remedial, penyelesaian tugas-tugas, pelaksanaan evaluasi dll. Kegiatan pelengkap dan penunjang pembelajaran adalah kegiatan ko-dan ekstra-kurikuler, layanan bimbingan dan konseling, pengembangan diri serta pembinaan-pembinaan lainnya. Secara lebih rinci segi-segi yang perlu dievaluasi dalam pelaksanaan kurikulum meliputi:

1) Persiapan Pembelajaran

a) Penyusunan Persiapan pembelajaran (RPP)

b) Penyusunan Hand Out

c) Pembuatan Media atau/ Alat Bantu Mengajar

2) Pelaksanaan Pembelajaran Teori
a) Proses Pembelajaran 
ISSN: 1829-6750 Inovasi Kurikulum, Agustus 2009, Thn. 6. Vol 6 Nomor: 2

- Metode atau Model Pembelajaran

- Pengaktivan siswa

- Pemberian Latihan

- Pemberian Tugas

b) Penggunaan Media dan Sumber

- Penggunaan Media atau Alat Bantu Pembelajaran

- Penggunaan buku, hand out, perpustakaan, sumber lainnya

3) Pelaksanaan Evaluasi

a) Evaluasi Proses pembelajaran

- Evaluasi kegaiatan siswa dalam partisipasi di kelas.

- Evaluasi kegiatan pengerjaan tugas dan latihan di kelas

- Evaluasi kegiatan siswa di luar kelas (praktek)

b) Evaluasi Hasil Belajar

- Evaluasi hasil belajar teori
- Evaluasi hasil penyelesaian tugas dan latihan

- Evaluasi hasil praktek di lapangan.

4) Evaluasi pelaksanaan dan bimbingan siswa,

- Segi/ masalah yang dibantu

- Jumlah siswa dibimbing

- Jumlah pembimbing

- Tehnik/ teori pemberian bimbingan.

- Kesulitan yang dihadapi dan cara mengatasinya.

4. Evaluasi Faktor-faktor Pendukung Pelaksanaan Kurikulum

Banyak faktor yang mendukung implementasi kurikulum pendidikan dasar namun faktor-faktor yang cukup dominan dalam menunjang efektivitas implementasinya adalah personalia, siswa, saranaprasaranaserta fasilitas, media 
ISSN: 1829-6750 Inovasi Kurikulum, Agustus 2009, Thn. 6 . Vol 6 Nomor: 2

dan sumber belajar, pengelolaan dan iklim belajar. Secara rinci faktor tersebut meliputi:

a) Personalia

Unsur Pimpinan

- Latar

Belakang pendidikan, pengalaman

- Kinerja unsur pimpinan

Guru
- Latar pendidikan pengalaman

- Kinerja guru belakang dan

d) Media dan sumber belajar

- Buku teks, majalah atau buku latihan

- Media elektronik-non elektronik

e) Pengelolaan kurikulum

e) Sistem adminstrasi pelaksanaan pembelajaran (Dokumen dan pelaporan nilai)

Staf Administrasi

- Latar belakang pendidikan, pengalaman dan kinerja

b) Siswa

- Kemampuan intelektual

- Kehidupan keluarga

- Kondisi ekonomi

g) Iklim Belajar

- Sikap dan motivasi kepala sekolah dan guru

- Sikap dan motivasi siswa

- Hubungan, kerjasama, ikatan emosi antar personil di sekolah

c) Sarana-prasarana dan fasilitas 
ISSN: 1829-6750 Inovasi Kurikulum, Agustus 2009, Thn. 6 . Vol 6 Nomor: 2

\section{Simpulan}

Ada empat wilayah evaluasi kurikulum pendidikan dasar, yaitu: evaluasi ide, evaluasi desain (dokumen), evaluasi implementasi, dan evaluasi faktor-faktor pendukung pelaksanaan kurikulum.

Evaluasi ide berkaitan dengan relevansi, kejelasan rumusan dan pemahaman ide kurikulum. Evaluasi desain diarahkan pada komponen visi, misi, tujuan, satuan pendidikan, struktur kurikulum, silabus dan Rencana Pelaksanaan Pembelajaran (RPP). Evaluasi implementasi berkaitan dengan perencanaan, pelaksanaan pembelajaran, penggunaan media dan sumber belajar serta proses dan hasil belajar. Sementara itu, evaluasi terhadap factorfaktor pendukung berkaitan dengan efektifitas personalia, siswa, sarana-prasarana, fasilitas, media, sumber relajar, pengelolaan dan iklim relajar.

\section{Daftar Pustaka:}

Hasan, S.H. ( 2008). Evaluasi Kurikulum. Bandung : Remaja Rosdakarya

Sa'ud, U.S. ( 2008). Pendidikan Dasar dan Menengah dalam Ilmu dan Aplikasi Pendidikan, Bandung : Pedagogiana Press.

Sukmadinata, N.S. (2006). Pengembangan Kurikulum.: Teori dan Praktek. Bandung : PT Remaja Rosdakarya 